\title{
In Vitro Cryopreservation of Date Palm Caulogenic Meristems
}

\author{
Lotfi Fki, Olfa Chkir, Walid Kriaa, Ameni Nasri, Emna Baklouti, \\ Raja B. Masmoudi, Alain Rival, Noureddine Drira, and Bart Panis
}

\begin{abstract}
Cryopreservation is the technology of choice not only for plant genetic resource preservation but also for virus eradication and for the efficient management of large-scale micropropagation. In this chapter, we describe three cryopreservation protocols (standard vitrification, droplet vitrification, and encapsulation vitrification) for date palm highly proliferating meristems that are initiated from vitro-cultures using plant growth regulator-free MS medium. The positive impact of sucrose preculture and cold hardening treatments on survival rates is significant. Regeneration rates obtained with standard vitrification, encapsulationvitrification, and droplet-vitrification protocols can reach 30, 40, and 70\%, respectively. All regenerated plants from non-cryopreserved or cryopreserved explants don't show morphological variation by maintaining genetic integrity without adverse effect of cryogenic treatment. Cryopreservation of date palm vitro-cultures enables commercial tissue culture laboratories to move to large-scale propagation from cryopreserved cell lines producing true-to-type plants after clonal field-testing trials. When comparing the cost of cryostorage and in-field conservation of date palm cultivars, tissue cryopreservation is the most cost-effective. Moreover, many of the risks linked to field conservation like erosion due to climatic, edaphic, and phytopathologic constraints are circumvented.
\end{abstract}

Key words Cryopreservation, Caulogenic meristems, Encapsulation, Vitrification

\section{Introduction}

Biotechnology has been used to propagate, improve, and preserve plant genetic resources [1-4]. In date palm (Phoenix dactylifera L.), biotechnological techniques have already been employed for in vitro propagation $[5,6]$. However, very few commercial tissue culture laboratories are now able to provide suitable quantities of date palm vitro-plants because it is recalcitrant to in vitro regeneration. In fact, date palm tissue cultures grow very slowly: the initiation phase may require more than 24 months, especially when low amounts of plant growth regulators are used to avoid potential somaclonal variation [7]. The presence of uncontrollable 
endophytic bacteria is another serious constraint hampering the large-scale micropropagation of date palm [8].

Cryopreservation refers to the long-term storage of living tissues at an ultra-low temperature $\left(-196{ }^{\circ} \mathrm{C}\right)$ so that it can be revived without loss of regeneration capacity and genetic fidelity. Various technical approaches exist in order to establish cryopreservation techniques. Some are based on a slow freezing and others are based on a rapid-freezing process known as vitrification which enables hydrated living cells to be cooled to cryogenic temperatures without ice formation $[1,2]$. All living cells suffer from severe osmotic stress and/or ice crystal damage during the freezing and thawing processes. The most effective ways to minimize such lethal effects are: (a) to use cryoprotective compounds in the culture medium prior to material freezing and (b) to control the transient cooling and warming rates during preservation. Cryopreservation circumvents problems related to the regular re-initiation of in vitro cultures and to the long-term maintenance of proliferating cultures that include risks of contamination, somaclonal variation, or loss of regeneration competency. Several studies have been published on date palm cryopreservation although research is still needed before routine use [9-11]. The successful cryopreservation of proliferating tissue can be of great interest for the development of commercial large-scale micropropagation strategies. Indeed, the availability as a safe backup of cryopreserved germplasm enables the sequential rejuvenation of cultures under production, thus circumventing unwanted drifts linked to long-term proliferation such as hormone habituation, loss of regeneration capacity, or somaclonal variation.

This chapter describes three cryopreservation protocols for date palm highly proliferating caulogenic meristems: standard vitrification, droplet-vitrification, and encapsulation-vitrification protocols.

\section{Materials}

\subsection{Plant Material}

2.2 Culture Medium and Cryopreservation Solutions
Adventitious caulogenic meristems (dedifferentiating cell aggregates) of date palm Deglet Noor cv. from in vitro cultures at an exponential proliferation phase, produced in RITA bioreactors (Fig. 1; see Note 1).

1. Basal culture medium: Murashige and Skoog (MS) medium [12] (Table 1).

2. Preculture medium (PM): Hormone-free MS medium containing $0.52 \mathrm{M}(180 \mathrm{~g} / \mathrm{L})$ sucrose and $8 \mathrm{~g} / \mathrm{L}$ agar.

3. Bioreactor medium (BM): Hormone-free liquid MS medium containing $0.2 \mathrm{M}(70 \mathrm{~g} / \mathrm{L})$ sucrose. 

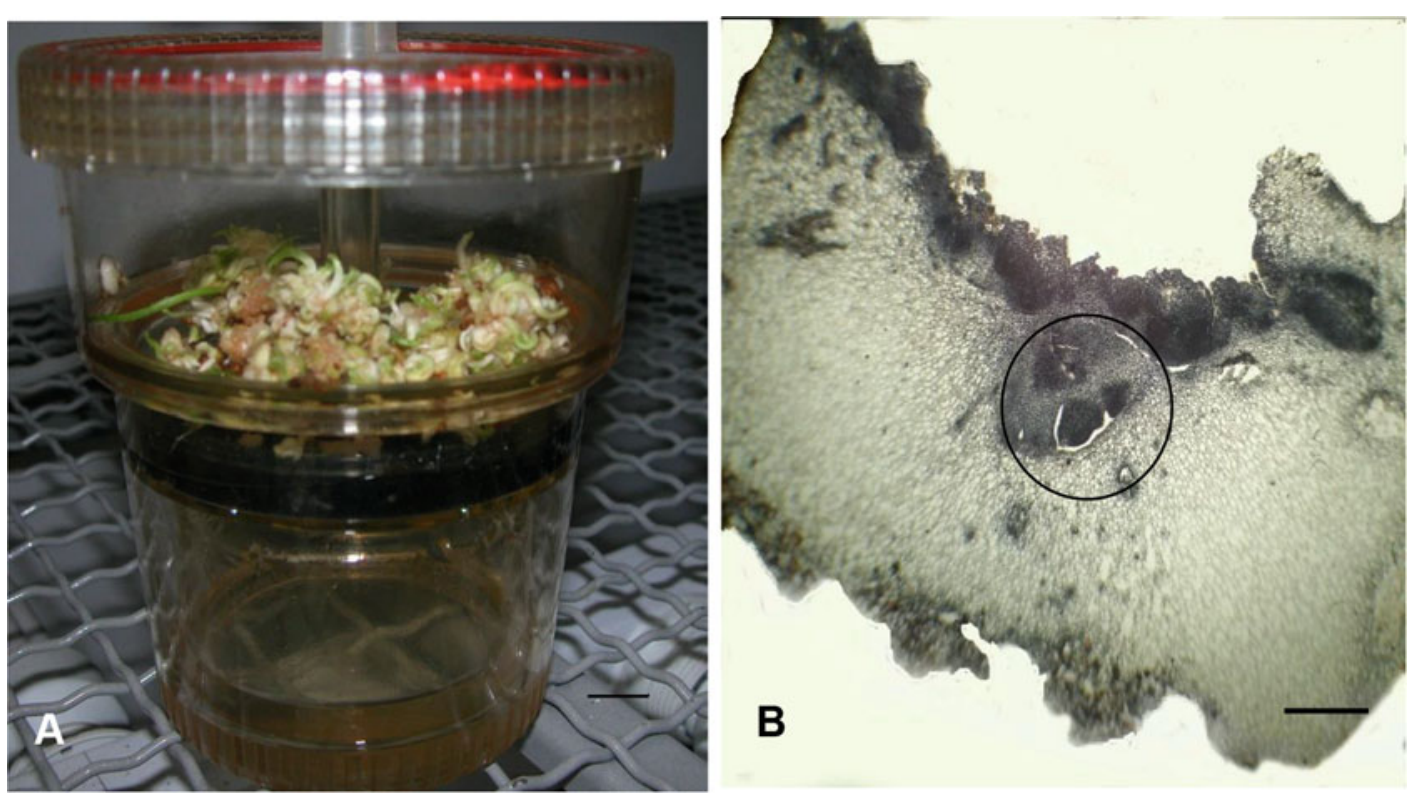

Fig. 1 (a) Caulogenic cultures growing in a RITA bioreactor, scale bar: $0.5 \mathrm{~cm}$, (b) histological section showing the explants (caulogenic meristems) used for cryopreservation, scale bar: $0.5 \mathrm{~mm}$

4. Loading solution (LS): Hormone-free liquid MS medium containing $2 \mathrm{M}(145.36 \mathrm{~mL} / \mathrm{L})$ glycerol and $0.4 \mathrm{M}(136.9 \mathrm{~g} / \mathrm{L})$ sucrose.

5. Vitrification solution (VS2) [13]: Hormone-free liquid MS medium containing $3.26 \mathrm{M}(236.93 \mathrm{~mL} / \mathrm{L})$ glycerol, $2.42 \mathrm{M}$ (136.66 mL/L) ethylene glycol, $1.9 \mathrm{M}(135.09 \mathrm{~mL} / \mathrm{L})$ dimethyl sulfoxide (DMSO), and 0.4 M (136.9 g/L) sucrose.

6. Recovery solution (RS): Hormone-free liquid MS medium containing 1.2 M (410.7 g/L) sucrose and $22 \mu \mathrm{M}(0.1 \mathrm{mg} / \mathrm{L})$ 2,4-dichlorophenoxyacetic acid (2,4-D).

7. Posttreatment medium (PTM): Hormone-free liquid MS medium containing $0.52 \mathrm{M}(180 \mathrm{~g} / \mathrm{L})$ sucrose.

8. Regeneration medium (RM): MS medium supplemented with $0.14 \mathrm{M}(50 \mathrm{~g} / \mathrm{L})$ sucrose, $22 \mu \mathrm{M}(0.1 \mathrm{mg} / \mathrm{L}) 2,4-\mathrm{D}$ and $8 \mathrm{~g} / \mathrm{L}$ agar.

9. Elongation medium (EM): Hormone-free liquid MS medium supplemented with $0.14 \mathrm{M}(50 \mathrm{~g} / \mathrm{L})$ sucrose.

10. Rooting medium (RoM): Liquid MS medium supplemented with $0.14 \mathrm{M}(50 \mathrm{~g} / \mathrm{L})$ sucrose and $4 \mathrm{mg} / \mathrm{L}$ Indole-3-butyric acid (IBA).

11. Solutions to adjust $\mathrm{pH}: 0.5 \mathrm{~N} \mathrm{NaOH}$ and $0.5 \mathrm{~N} \mathrm{HCl}$. 
Table 1

Composition of MS medium [12]

\begin{tabular}{|c|c|}
\hline Medium composition & Concentration (mg/L) \\
\hline \multicolumn{2}{|c|}{ Major inorganic nutrients } \\
\hline $\mathrm{Mg} \mathrm{SO}_{4} \cdot 7 \mathrm{H}_{2} \mathrm{O}$ & 370 \\
\hline $\mathrm{KH}_{2} \mathrm{PO}_{4}$ & 170 \\
\hline $\mathrm{KNO}_{3}$ & 1900 \\
\hline $\mathrm{CaCl}_{2} \cdot 2 \mathrm{H}_{2} \mathrm{O}$ & 440 \\
\hline $\mathrm{NH}_{4} \mathrm{NO}_{3}$ & 1650 \\
\hline \multicolumn{2}{|c|}{ Minor inorganic nutrients } \\
\hline $\mathrm{MnSO}_{4} \cdot 4 \mathrm{H}_{2} \mathrm{O}$ & 22.3 \\
\hline $\mathrm{ZnSO}_{4} \cdot 7 \mathrm{H}_{2} \mathrm{O}$ & 8.6 \\
\hline $\mathrm{H}_{3} \mathrm{BO}_{3}$ & 6.2 \\
\hline KI & 0.83 \\
\hline $\mathrm{Na}_{2} \mathrm{MoO}_{4} \cdot 2 \mathrm{H}_{2} \mathrm{O}$ & 0.25 \\
\hline $\mathrm{CuSO}_{4} \cdot 5 \mathrm{H}_{2} \mathrm{O}$ & 0.025 \\
\hline $\mathrm{CoCl}_{2} \cdot 6 \mathrm{H}_{2} \mathrm{O}$ & 0.025 \\
\hline \multicolumn{2}{|l|}{ Iron source } \\
\hline $\mathrm{Fe} \mathrm{SO}_{4} \cdot 7 \mathrm{H}_{2} \mathrm{O}$ & 27.84 \\
\hline $\mathrm{Na}_{2}$ EDTA & 37.24 \\
\hline \multicolumn{2}{|c|}{ Vitamins and amino acids } \\
\hline Nicotinic acid & 0.5 \\
\hline Pyridoxine $\mathrm{HCl}$ & 0.5 \\
\hline Thiamine $\mathrm{HCl}$ & 0.1 \\
\hline Myo-inositol & 100 \\
\hline Glycine & 2 \\
\hline Glutamine & 200 \\
\hline
\end{tabular}

2.3 Reagents

1. Liquid nitrogen.

2. Fixative solution (FS): Chromic acid $5 \mathrm{~g} / \mathrm{L}$, glacial acetic acid $50 \mathrm{~mL} / \mathrm{L}$ formaldehyde $150 \mathrm{~mL} / \mathrm{L}$, and ethanol $50 \mathrm{~mL} / \mathrm{L}$.

3. Hematoxylin Solution (HS): $100 \mathrm{mg} / \mathrm{L}$ hematoxylin in ethanol.

4. Staining solution (SS): $100 \mathrm{~mL} / \mathrm{L}$ hematoxylin and $100 \mathrm{~mL} / \mathrm{L}$ glycerol. 
1. Horizontal laminar flow hood.

2. RITA Bioreactors.

3. Aluminum foil.

4. Micropipette.

5. Cryotubes.

6. Microfilters.

7. Rotary microtome.

8. Autoclave.

\section{Methods}

\subsection{Culture Media Preparation}

3.2 Caulogenic Cultures Maintenance

\subsection{Histology}

3.4 Cryopreservation Solutions Preparation
1. Refer to Subheading 2.2 and Table 1 for the composition of culture media, mix components, and adjust the $\mathrm{pH}$ to 5.8 .

2. Sterilize all media for $15 \mathrm{~min}$ using a standard autoclave.

1. For caulogenic vitro-cultures multiplication, use RITA bioreactors for the temporary immersion of cultures in liquid medium. The RITA vessel is made of two compartments: the explants are cultivated in the upper compartment, and the lower one holds the liquid medium (Fig. la).

2. Cultivate 6-bud clusters per bioreactor using $200 \mathrm{~mL}$ BM. The immersion cycle is 15 min every $24 \mathrm{~h}$, and the culture medium is renewed once every 4 months (see Note 2).

3 . Incubate cultures in a growth chamber set at $28^{\circ} \mathrm{C}$ and $16-\mathrm{h}$ photoperiod $\left(30 \mu \mathrm{mol} / \mathrm{m}^{2} / \mathrm{s}\right)$.

1. Put the explant in the fixative solution for $24 \mathrm{~h}$.

2. Dehydrate gradually the explant with ethanol solutions (50, $60,70,80,90$, and $100 \%)$ for $1 \mathrm{~h}$ each.

3 . Embed the explant in paraffin.

4. Perform serial sections $(10 \mu \mathrm{m})$ with a rotary microtome.

5. Mount the sections on glass slides and stain with SS solution for $4 \mathrm{~h}$.

1. Refer to Subheading 2.2 for the composition of cryopreservation solutions, mix components of each solution, and adjust the $\mathrm{pH}$ to 5.8 .

2. Sterilize all solutions using $0.22 \mu \mathrm{m}$ membrane filters, and keep them at $-20{ }^{\circ} \mathrm{C}$. 
3.5 Cryopreservation Protocols

3.5.1 Standard Vitrification Protocol
1. Excise the caulogenic meristems from tissue showing bud initiation (Fig. 1b; see Note 3 ).

2. Culture tissue-bearing caulogenic meristems on preculture medium (PM) or incubate them at $4{ }^{\circ} \mathrm{C}$ (cold hardening treatment) for 2 days (see Notes 3 and 4 ).

1. Transfer the caulogenic meristems (explants) to a Petri dish containing $15 \mathrm{~mL}$ loading solution (LS), and incubate at room temperature for $20 \mathrm{~min}$ (Fig. 2).

Meristems sucrose preculture

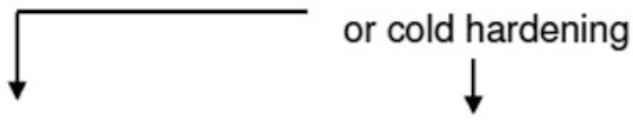

\section{Standard vitrification Droplet-vitrification}

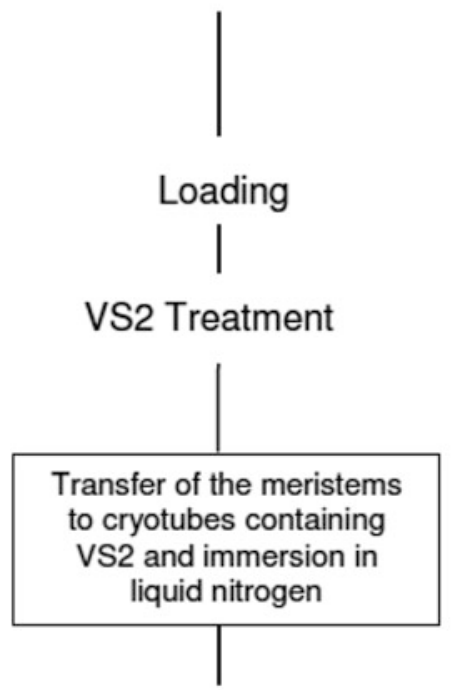

Thawing in a water bath

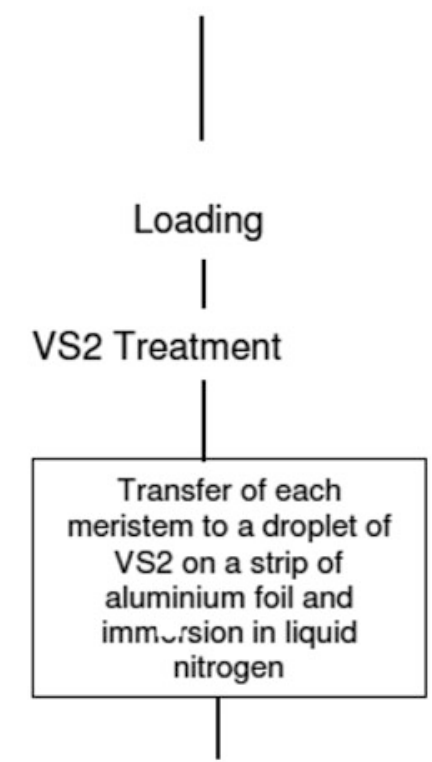

Thawing in $\mathrm{RS}$ at $25^{\circ} \mathrm{C}$

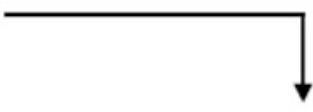

Encapsulation-vitrification

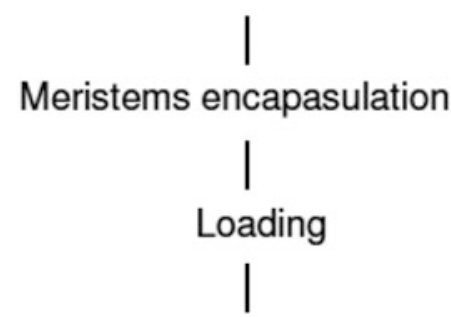

VS2 Treatment

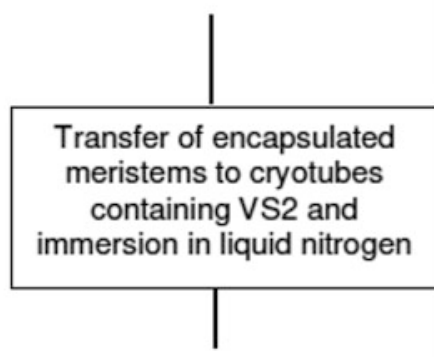

Thawing in a water bath

RS Treatment

Transfer to regeneration medium

Determination of viability rates

Fig. 2 Description of the cryopreservation protocols. $L S$ loading solution; VS vitrification solution; $R S$ recovery solution 
3.5.2 Droplet-Vitrification Protocol

3.5.3 EncapsulationVitrification Protocol
2. Replace the loading solution by ice-cooled VS2 solution.

3. Put the explants in a Petri dish containing VS2 solution for $30 \mathrm{~min}$ at $0{ }^{\circ} \mathrm{C}$.

4. Transfer the explants into $2 \mathrm{~mL}$ cryotubes containing $0.5 \mathrm{~mL}$ VS2, and then plunge them into liquid nitrogen.

5. After $\mathrm{l} \mathrm{h}$ in liquid nitrogen storage, thaw the cryotubes in a water bath at $40{ }^{\circ} \mathrm{C}$ for $2 \mathrm{~min}$.

6. Put the explants in a Petri dish containing RS at room temperature for $15 \mathrm{~min}$.

7. Place the explants onto two sterile filter papers on top of PTM.

8 . Incubate the explants in the dark at $28^{\circ} \mathrm{C}$.

9. After 2 days, transfer the explants onto RM.

1. Transfer explants (tissue-bearing caulogenic meristems) to $15 \mathrm{~mL}$ loading solution (LS) for $20 \mathrm{~min}$.

2. Replace the loading solution by ice-cooled VS2 solution.

3. Place the explants in a Petri dish containing VS2 solution for $30 \mathrm{~min}$ at $0{ }^{\circ} \mathrm{C}$.

4. Transfer the explants to a droplet of VS2 on a strip of aluminum foil $(3 / 7 \mathrm{~mm})$, and then plunge them into liquid nitrogen.

5. For permanent cryostorage, transfer frozen foil strips to $2 \mathrm{~mL}$ cryotubes filled with liquid nitrogen.

6. After $1 \mathrm{~h}$ in LN storage, treat in a Petri dish the explants by RS at room temperature for $15 \mathrm{~min}$.

7. Place the explants onto two sterile filter papers on top of PTM.

8 . Incubate the explants in the dark at $28^{\circ} \mathrm{C}$.

9. After 2 days, transfer the explants onto RM (see Note 5 ).

1. Put the explants bearing caulogenic meristems into previously autoclaved 3\% (w/v) sodium alginate, dissolved in MS medium amended with $0.2 \mathrm{M}(68.4 \mathrm{~g} / \mathrm{L})$ sucrose without $\mathrm{CaCl}_{2}$. Suck them up with a micropipette, and drop them gently into $75 \mathrm{mM} \mathrm{CaCl} \cdot 2 \mathrm{H}_{2} \mathrm{O}$ in $\mathrm{MS}$ medium supplemented with $0.2 \mathrm{M}(68.4 \mathrm{~g} / \mathrm{L})$ sucrose (see Note 6).

2. Transfer the encapsulated plant tissue into the loading solution for $20 \mathrm{~min}$ (Fig. 2).

3. Replace the loading solution by ice-cooled VS2 solution.

4. Hold the encapsulated explants with VS2 solution for $60 \mathrm{~min}$ at $0{ }^{\circ} \mathrm{C}$. 


\subsection{Plant \\ Regeneration Protocol}

5. Transfer the encapsulated explants into $2 \mathrm{~mL}$ cryotubes containing $0.5 \mathrm{~mL} \mathrm{VS2}$, and then plunge them into liquid nitrogen $(\mathrm{LN})$.

6. After $\mathrm{l} \mathrm{h}$ in LN, thaw the cryotubes containing the alginate beads in a water bath at $40{ }^{\circ} \mathrm{C}$ for $2 \mathrm{~min}$.

7. Put the beads in a Petri dish containing RS at $25^{\circ} \mathrm{C}$ for $15 \mathrm{~min}$.

8. Place the alginate beads onto two sterile filter papers on top of PTM.

9. Incubate the beads in the dark at $28^{\circ} \mathrm{C}$.

10. After 2 days, transfer the explants onto RM to get buds (Fig. 3a; see Note 7).

1. To generate multiple bud clusters, subculture the obtained buds onto RM medium once every 2 months for many times.

2. For shoot elongation, transfer bud clusters onto a thin film of liquid RM medium once every 2 months for many times (Fig. 3b).

3. For shoots rooting, transfer shootlets $(5-10 \mathrm{~cm}$ height) onto RoM medium.

\section{Notes}

1. A caulogenic meristem is a tissue that can produce an adventitious bud. It is important to point out that this protocol is also effective for two other tested date palm cultivars, Barhee and Khenaizi.

2. Cultivation of date palm shoots in RITA vessels proliferates efficiently by using liquid medium and the control of the gaseous environment of in vitro cultures [14].

3 . In this protocol, only small explants $(<2 \mathrm{~mm})$ are able to tolerate cryo-treatments [15].

4. The beneficial effect of both sucrose preculture and cold hardening on post-thaw regeneration is clearly demonstrated $[16,17]$. Sucrose treatments increase the osmolarity of intracellular solutes, thus reducing the detrimental effect of VS2 and the formation of intracellular ice upon subsequent immersion of the explants in liquid nitrogen. Both sucrose and cold acclimation treatments increase proline content in date palm tissue.

5. The droplet vitrification is the most efficient strategy for the cryo-banking of date palm tissue. The highest regeneration rates obtained with the standard vitrification, encapsulationvitrification, and droplet-vitrification protocols are 30,40, and $70 \%$, respectively $[1]$. 

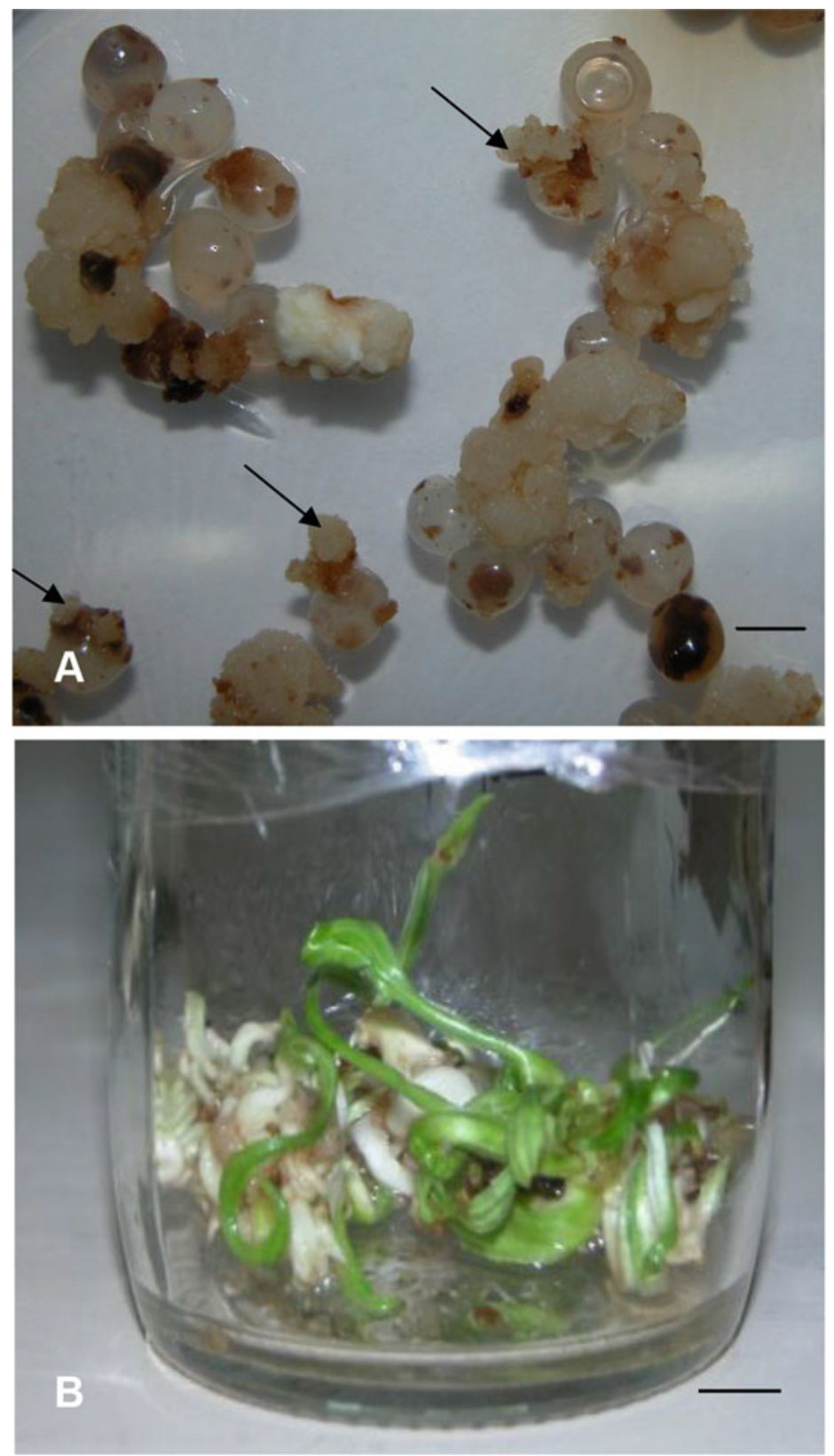

Fig. 3 Regrowth (see arrows) of date palm caulogenic meristems after cryopreservation using encapsulationvitrification protocol. (a) 2 months after thawing, (b) 6 months after thawing, scale bar: $0.5 \mathrm{~cm}$

6. Alginate is nontoxic to date palm meristems and protects efficiently against cryodamages [1].

7. We have to wait for $3-5$ months to produce buds from survived meristems [18]. 
Acknowledgments

This work was supported financially by the Ministry of Higher Education and Scientific Research in Tunisia, the International Atomic Energy Agency (IAEA), the Arab League Educational, Cultural and Scientific Organization (ALECSO), the European Cooperation in Science and Technology (COST), the Swiss National Science Foundation (SNSF), and the Technical Centre of Dates in Tunisia (TCDT).

\section{References}

1. Fki L, Bouaziz N, Chkir O, BenjemaaMasmoudi R, Swennen R, Rival A, Drira N, Panis B (2013) Cold hardening and sucrose treatment improve cryopreservation of date palm meristems. Biol Plant 57(2):375-379

2. Salmaa M, Fki L, Engelmann-Sylvestrea I, Niinod T, Engelmann F (2014) Comparison of droplet-vitrification and D-cryoplate for cryopreservation of date palm (Phoenix dactylifera L.) polyembryonic masses. Sci Hortic 179:91-97

3. Panis B, Piette B, Swennen R (2005) Droplet vitrification of apical meristems: a cryopreservation protocol applicable to all Musaceae. Plant Sci 168:45-55

4. Engelmann F (2004) Plant germplasm cryopreservation: progress and prospects. In Vitro Cell Dev Biol Plant 40:427-433

5. Drira N, Benbadis A (1985) Vegetative multiplication of date palm (Phoenix dactylifera L.) by reversion of in vitro cultured female flower buds. J Plant Physiol 119:227-235

6. Fki L, Masmoudi R, Drira N, Rival A (2003) An optimised protocol for plant regeneration from embryogenic suspension cultures of date palm (Phoenix dactylifera L.) cv. DegletNour. Plant Cell Rep 21:517-524

7. Cohen Y (2011) Molecular detection of somaclonal variation in date palm. In: Jain SM, Al-Khayri JM, Johnson DV (eds) Date palm biotechnology. Springer, Dordrecht, pp 221-235

8. Fki L, Kriaa W, Sahnoun N, Bouaziz N, Masmoudi R, Drira N (2010) Regeneration of date palm in vitro plantlets at pilot scale: production plans and constraints remediation. In: Aberlenc-Bertossi F (ed) Biotechnologies du palmier dattier. IRD, Montpellier, pp 195-214

9. Bagniol S, Engelmann F (1992) Effect of thawing and recovery conditions on the regrowth of meristems of date palm Phoenix dactylifera L.
Var. Bou Sthammi noir after cryopreservation in liquid nitrogen. CryoLetters 13:253-260

10. Mycock DJ, Wesley-Smith J, Berjak P (1995) Cryopreservation of somatic embryogenesis of four species with and without cryoprotectant pre-treatment. Ann Bot 75:331-336

11. Fki L, Bouaziz N, Sahnoun N, Swennen R, Drira N, Panis B (2011) Palm cryobanking. CryoLetters 32:451-462

12. Murashige T, Skoog F (1962) A revised medium for rapid growth and bioassays with tobacco tissue cultures. Physiol Plant 15:473-497

13. Sakai A, Engelmann F (2007) Vitrification, encapsulation-vitrification and dropletvitrification: a review. CryoLetters 28:151-172

14. Afreen F (2006) Temporary immersion bioreactor: engineering considerations and applications in plant micropropagation. In: Dutta Gupta S, Ibaraki Y (eds) Plant tissue culture engineering. Springer, Dordrecht, pp 187-201

15. Baek HJ, Kim HH, Cho EG, Chae YA, Engelmann F (2003) Importance of explant size and origin and of preconditioning treatments for cryopreservation of garlic shoot apices by vitrification. CryoLetters 24:381-388

16. Panis B, Strosse H, Van Den Hende S, Swennen R (2002) Sucrose preculture to simplify cryopreservation of banana meristem cultures. CryoLetters 23:375-384

17. Ganino T, Silvanini A, Beghé D, Benelli C, Lambardi M, Fabbri A (2012) Anatomy and osmotic potential of the Vitis rootstock shoot tips recalcitrant to cryopreservation. Biol Plant 56:78-82

18. Fki L, Bouaziz N, Kriaa W, BenjemaaMasmoudi R, Gargouri-Bouzid R, Rival A, Drira N (2011) Multiple bud cultures of 'Barhee' date palm (Phoenix dactylifera) and physiological status of regenerated plants. J Plant Physiol 168:1694-1700 